\title{
Prevalence of Neck Pain among Athletes: A Systematic Review
}

\author{
Pardis Noormohammadpour ${ }^{1,2}$, Farbod Farahbakhsh ${ }^{1,2}$, Farzin Farahbakhsh ${ }^{3}$, \\ Mohsen Rostami ${ }^{4}$, Ramin Kordil, ${ }^{2}$ \\ ${ }^{1}$ Sports Medicine Research Center, Neuroscience Institute, Tehran University of Medical Sciences, Tehran, Iran \\ ${ }^{2}$ Department of Sports and Exercise Medicine, School of Medicine, Tehran University of Medical Sciences, Tehran, Iran \\ ${ }^{3}$ Department of neurosurgery, Shariati Hospital, Tehran University of Medical Sciences, Tehran, Iran \\ ${ }^{4}$ Brain and Spinal Cord Injuries Research Center, Neuroscience Institute, Tehran University of Medical Sciences, Tehran, Iran
}

\begin{abstract}
Many studies have investigated the prevalence of neck pain (NP) and its risk factors in the general population. However, the prevalence of NP among athletes has not yet been systematically investigated. We aimed to systematically review the prevalence of NP in athletes. A comprehensive search was conducted in September 2015 using PubMed, Ovid SP Medline, ISI, and Google Scholar. We included studies in English that reported the prevalence of NP in an athletic population during a defined period of time. We assessed the risk of bias in studies due to various definitions of NP, response rates, and reliability of the study instruments. Two reviewers independently assessed the studies' quality and performed data extraction. Of 1,675 titles identified, eight articles were assessed for risk of bias, and six with low or moderate risk were included. NP was shown to be prevalent in athletes, with a 1-week prevalence ranging from $8 \%$ to $45 \%$, a 1 -year prevalence ranging from $38 \%$ to $73 \%$, and a lifetime prevalence of about $48 \%$. The prevalence of $\mathrm{NP}$ in athletes is high. More studies regarding the prevalence and risk factors of NP may be useful for planning educational programs and developing appropriate rehabilitation protocols and preventive guidelines. Researchers are encouraged to perform epidemiologic studies in athletes with a low risk of bias.
\end{abstract}

Keywords: Neck pain; Sports; Athletes; Prevalence

\section{Introduction}

Neck pain (NP) is a common musculoskeletal problem with a lifetime prevalence of $14 \%-70 \%$ in the general population [1,2]. Based on the Global Burden of Disease report, NP accounts for the fourth highest number of years lived with disability [3], and its direct and indirect economic costs have encouraged researchers to study the prevalence and risk factors of NP in the general popula- tion $[1,2,4-6]$.

Although the prevalence of NP among athletes could be considered similar to that in the general population, their sports-specific injuries may put them at a higher risk of NP [7]. Previous studies have suggested a U-shaped curve relationship between physical activity and low back pain, indicating that both low and high levels of physical activity can cause low back pain $[8,9]$. However, studies in this field of relation between physical activity and NP are

Received Jan 17, 2018; Revised Mar 7, 2018; Accepted Apr 17, 2018

Corresponding author: Ramin Kordi

Department of Sports and Exercise Medicine, Sports Medicine Research Center, Tehran University of Medical Sciences, No 7, Al-e Ahmad St., Tehran, Iran

Tel: +98-21-88630227-8, Fax:+98-21-88003539, E-mail: ramin_kordi@tums.ac.ir 
scant. Athletes spend more time in sports activities, and they experience higher mechanical loads on their spine. Such musculoskeletal stress can accumulate over years of participation in professional sports from adolescence to adulthood, depending on the type, intensity, frequency, and duration of sports [9]. Many studies have investigated the prevalence of low back pain in athletes [9-11]. Because similar studies of NP in athletes are scarce, some studies have investigated the prevalence of NP in athletic populations. However, such studies may suffer from methodological limitations. Recall bias, low response rates, inconsistent use of definitions of NP [12,13], differences in target populations [14-16], and differences in the duration and severity of NP $[15,16]$ make it difficult to draw a sound conclusion regarding the prevalence of NP in athletes.

To the best of our knowledge, there is no systematic review of the prevalence of NP in athletes. The aim of this study was to systematically review the existing literature regarding the prevalence of NP in athletes and summarize it based on variations in time, place, and field of sports.

\section{Materials and Methods}

We conducted this systematic review to answer the question: What is the prevalence of NP among athletes? We systematically reviewed the literature up to September 2015 based on PRISMA guidelines [17,18].

\section{Eligibility criteria}

We included studies that reported the prevalence of NP in a particular athletic population at a given time, such as at one point in time, during one year, and over a lifetime. We excluded articles not in English, studies that included only patients with NP, and case reports and nonoriginal studies.

\section{Search strategy}

A comprehensive literature search was conducted in September 2015 using PubMed (1950 to present), Ovid SP Medline (1950 to present), ISI (1982 to present), and Google Scholar, based on specific search strategies for epidemiological research. We used the following key words for our search in different combinations: "neck pain," "neck ache," "cervicalgia," "cervicodynia," "neckache," "cervical pain," and "sport," "athlete," plus the names of different sports, including those presented by the International Olympics Committee. Search strategies were modified as necessary for each specific database.

All the manuscripts found throughout our search process were imported into Endnote X6 (Thomson Reuters, Philadelphia, PA, USA), and duplicates were removed. The titles and abstracts of identified studies were scrutinized for eligibility, and full-text versions of selected studies were collected for further assessment. Also, in order to avoid bias, reference lists of selected manuscripts and review papers were manually searched to identify additional relevant articles.

\section{Quality appraisal}

Two reviewers (FF and FF) independently assessed the

Table 1. The critical appraisal tool of the study [19]

\section{Content}

1. Was the study's target population a close representation of the national population in relation to relevant variables, e.g.,
age, gender, occupation?
2. Was the sampling frame a true or close representation of the target population?
3. Was some form of random selection used to select the sample, or, was a census undertaken?
4. Was the likelihood of non-response bias minimal?
5. Were data collected directly from the subjects (as opposed to a proxy)?
6. Was an acceptable case definition used in the study?
7. Was the study instrument that measured the parameter of interest (e.g., prevalence of neck pain) shown to have reliability
and validity (if necessary)?
8. Was the same mode of data collection used for all subjects?
9. Was the length of the shortest prevalence period for the parameter of interest appropriate
10. Were the numerator(s) and denominator(s) for the parameter of interest appropriate?


external and internal validity of the included studies using a standardized and reliable bias assessment tool that was developed for prevalence studies (Table 1) [19]. Disagreements in ratings of bias assessment were discussed between the two reviewers, and if they could not reach an agreement, a third reviewer (PN) was consulted to achieve a consensus.

\section{Data extraction}

A data extraction form was designed before the study, and a group of three academic experts assessed its face validation. All data were extracted from the included studies with a low-to-medium risk of bias and independently entered into the form by two reviewers (FF and FF), based on a standardized method. Any disagreements were resolved by consensus, as previously described. The prevalence of NP by age group and gender was also extracted if the relevant data were reported. Because of predicted heterogeneity among the included studies, we did not consider meta-analysis of the data.

\section{Results}

\section{Literature search}

The electronic literature search identified 1,675 records, and after removal of duplicates, 1,214 titles and abstracts were checked. Two articles were added after screening of references (Fig. 1). Following the full-text review of 34 articles, 26 articles were excluded and eight articles were considered for assessment of bias [12-16,20-22].

\section{Methodological quality}

All disagreements between reviewers were resolved through consensus, and evaluated articles were categorized as having low, moderate, or high risk of bias, based on their bias assessment scores. The measured risk of bias was high for two studies, moderate for four studies, and low for two

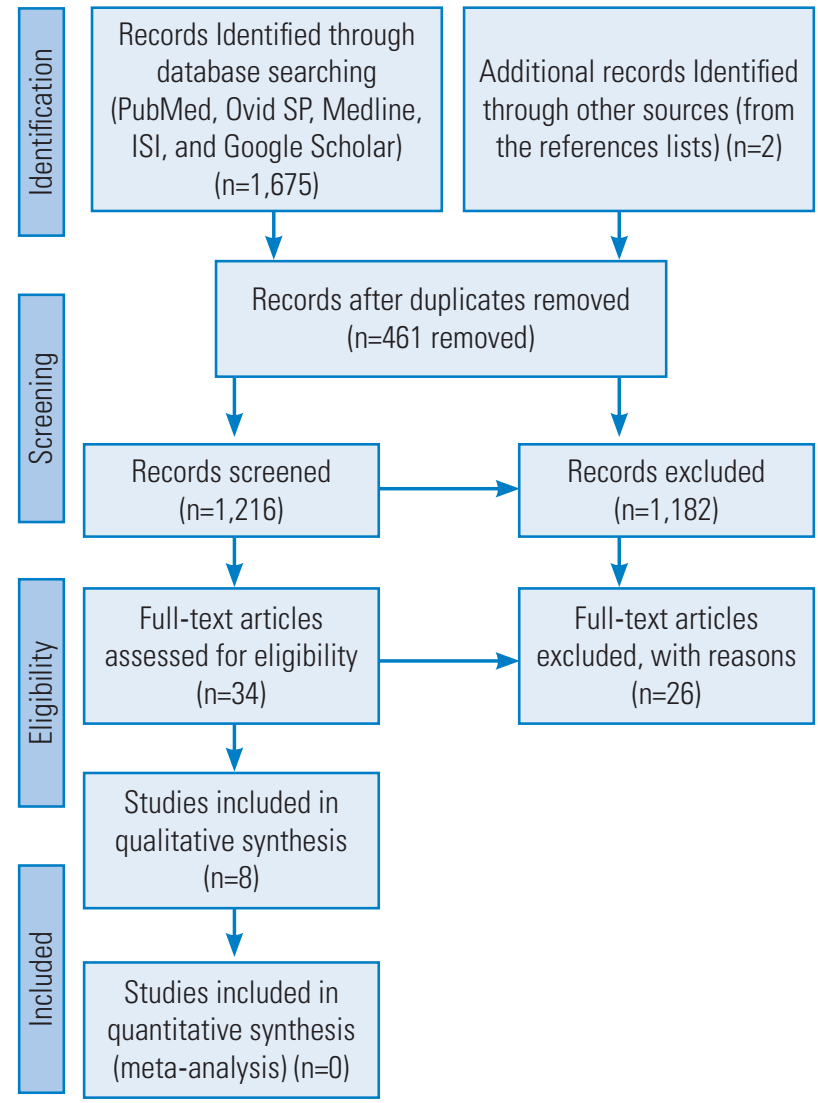

Fig. 1. Flowchart for search results and study selection.

Table 2. Critical appraisal of epidemiological studies

$\begin{array}{llllllllllllll}\text { Study } & 0.1 & 0.2 & 0.3 & 0.4 & 0.5 & 0.6 & 0.7 & 0.8 & 0.9 & 0.10 & \text { Overall risk of bias } \\ \text { Weiss [14] (1985) } & \text { High } & \text { High } & \text { High } & \text { High } & \text { Low } & \text { High } & \text { High } & \text { Low } & \text { High } & \text { Low } & \text { High } & \\ \text { Villavicencio et al. [15] (2006) } & \text { Low } & \text { High } & \text { High } & \text { High } & \text { Low } & \text { High } & \text { High } & \text { Low } & \text { High } & \text { Low } & \text { Moderate } \\ \text { Villavicencio et al. [13] (2007) } & \text { Low } & \text { High } & \text { High } & \text { High } & \text { Low } & \text { High } & \text { High } & \text { Low } & \text { High } & \text { Low } & \text { Moderate } \\ \text { Jonasson et al. [12] (2011) } & \text { High } & \text { High } & \text { Low } & \text { Low } & \text { Low } & \text { High } & \text { High } & \text { Low } & \text { Low } & \text { Low } & \text { Moderate } \\ \text { Nilsson et al. [16] (2013) } & \text { Low } & \text { Low } & \text { Low } & \text { Low } & \text { Low } & \text { Low } & \text { Low } & \text { Low } & \text { Low } & \text { Low } & \text { Low } & \\ \text { Bratland-Sanda et al. [20] (2015) } & \text { Low } & \text { Low } & \text { High } & \text { High } & \text { Low } & \text { High } & \text { Low } & \text { Low } & \text { Low } & \text { Low } & \text { Moderate } \\ \text { Legault et al. [21] (2015) } & \text { Low } & \text { Low } & \text { High } & \text { High } & \text { Low } & \text { Low } & \text { Low } & \text { Low } & \text { Low } & \text { Low } & \text { Low } & & \text { High } \\ \text { Wójcik et al. [22] (2015) } & \text { High } & \text { High } & \text { High } & \text { High } & \text { Low } & \text { High } & \text { High } & \text { Low } & \text { High } & \text { Low } & \text { High } & \end{array}$

Low risk of bias: more research is very unlikely to alter our confidence in the estimate. Moderate risk of bias: more research is likely to have a significant impact on our confidence in the estimate and may alter the estimate. High risk of bias: more research is very likely to have a considerable impact on our confidence in the estimate and is likely to alter the estimate. 


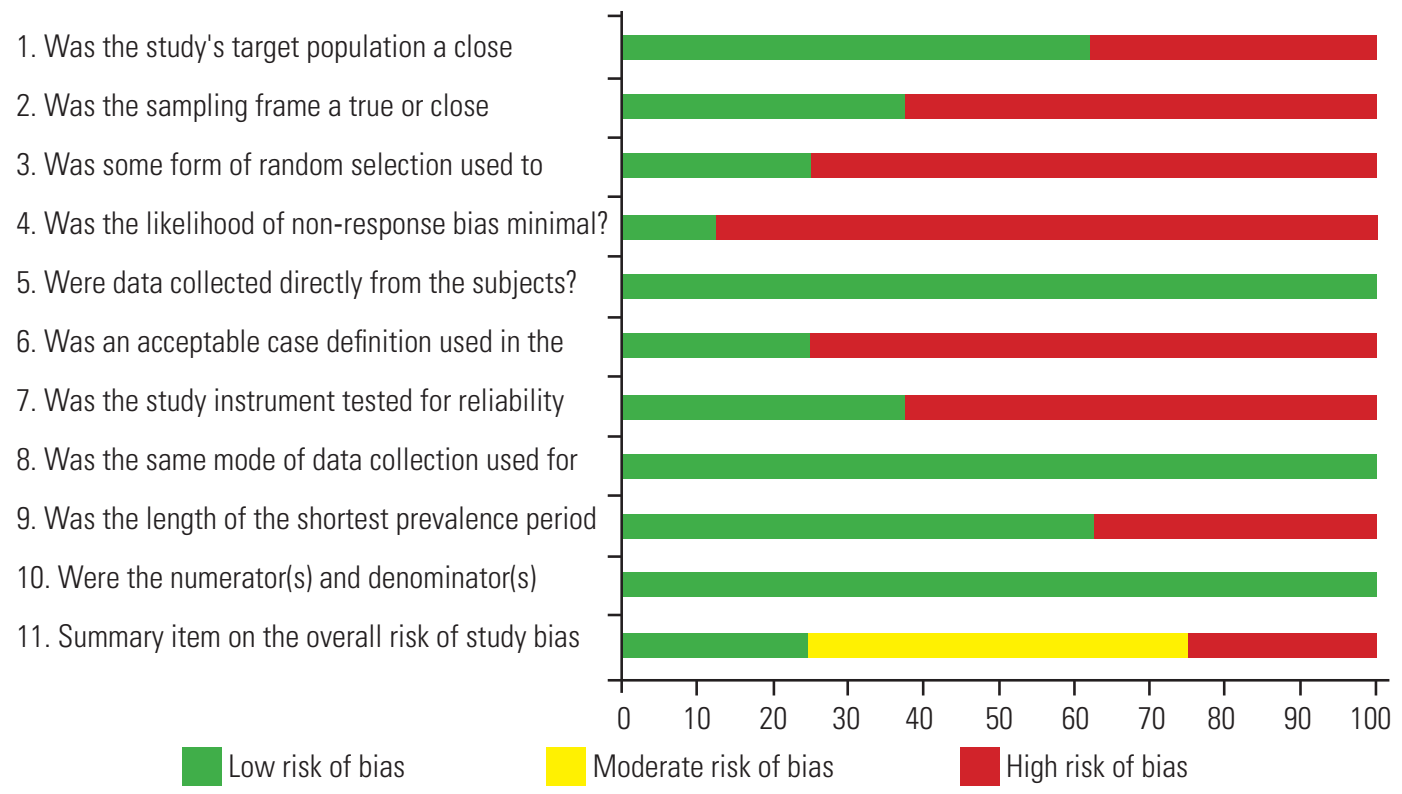

Fig. 2. Rating for each risk of bias item ( $n=8$ studies).

studies. Table 2 presents the methodological quality assessments for each article, and Fig. 2 shows the ratings of the studies according to each item of the risk assessment tool. Finally, studies with high levels of bias were excluded.

\section{Characteristics of included studies}

Data were extracted from six studies with low-to-moderate risk of bias. Table 3 presents the characteristics and detailed descriptions of these studies.

\section{Prevalence of neck pain}

The prevalence of NP was most commonly reported for a period of one year $(n=2)$ or for a lifetime $(n=2)$ (Table 4). The prevalence of NP during one year ranged between $38 \%$ and $73 \%$, with a mean of $45.9 \%$ [12,16]. Lifetime prevalence (only in triathlon athletes) ranged from 47.6 to 48.3 years $[13,15]$. Wrestlers reported the highest rate of one-year prevalence of NP (73\%) and orienteering athletes the lowest (38\%) among investigated sports fields [12]. The prevalence of NP was also assessed for periods of one week (ranging from $8 \%$ to $45 \%$ ), one month (ranging from $38 \%$ to $43 \%)$, and 6 months (26.3\%) [12,20,21].

\section{Definitions of neck pain}

Table 5 shows the definitions of NP used by the studies. Two studies used a posterior view of the anatomic region for clarification of the definition of NP [16,21]. However, no study used the side view as mandated by the Neck Pain Task Force consensus [23]. Studies by Villavicencio et al. [13] presented definitions only for the latest duration of NP (acute, subacute, and chronic episodes) in triathlon athletes [15]. Only three studies used an acceptable definition of NP.

\section{Discussion}

\section{Key findings}

This study showed that similar to the general population, the prevalence of NP is high among athletes. Previously, Yang et al. [7] showed that participation in sports significantly increased the odds ratio for NP to 1.7. Limited studies have investigated the prevalence of NP among athletes in different fields of sports; wrestlers reported the highest one-year prevalence of NP (73\%) [12]. Wrestling is a contact sport with specific movements that put a large amount of load on the head and place the neck in an extreme range of motions during common techniques such as takedown (an inseparable part of this sport) [24]. Therefore, such a high prevalence of NP could be expected in wrestlers. In the second rank are ice hockey players, for whom the prevalence of NP is 65\% [12]. Axial loading of the neck during contact could lead to injury to bony and soft tissue structures and increase the prevalence of NP in these athletes [25]. However, because of the lack of 


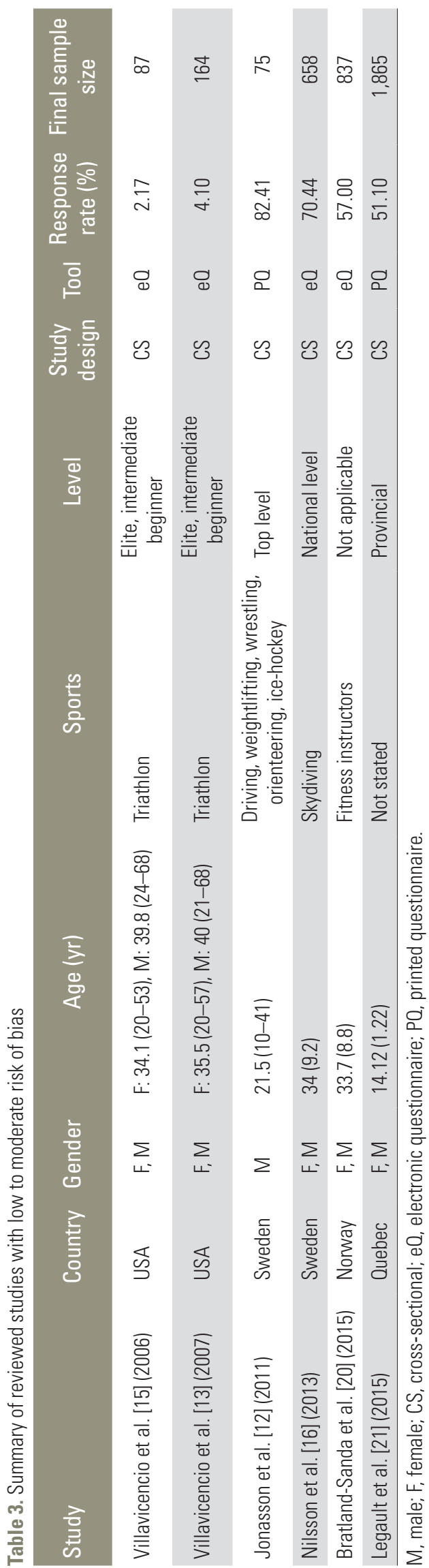

reports of NP in contact sports, we could not compare the prevalence of NP in these sports with that in other similar sports, such as American football. The lowest one-year prevalence of NP is associated with orienteering. Because of the noncontact nature of this running-related endurance sport, neck injuries in orienteering are rare [26].

The only available reports of the lifetime prevalence of NP were from triathlon athletes, showing a prevalence of approximately $48 \%[13,15]$. Overuse and inappropriate positions during the cycling segment of this sport (which includes swimming, cycling, and running) have been proposed as responsible factors for NP [27].

\section{Risk of bias}

About one-third of the studies in our review $(n=3)$ [20-22] were published in 2015, which may illustrate the increased attention to this problem among athletes in the United States and Europe. Concerning popular sports diversity and social and economic distinctions of different countries, studies of the prevalence of NP and possible risk factors among athletes in the rest of the world might increase our knowledge of NP in athletes and help us provide new sport-specific preventive and educational plans. Therefore, we recommend more studies in this field.

Most epidemiological studies in this field have various risks of bias, such as reliability of study instruments [12$15,22]$, low response rates [13,15,20-22], and problems in case definitions $[12-15,20,22]$. With regard to case definition, only half of the considered studies $[13,15,16,21]$ reported their definition of NP, and only two studies [16,21] used an acceptable definition [23], with a figure showing the location of the pain. Some recent epidemiologic studies of low back pain in the general population have presented guidelines, including datasets or definitions $[28,29]$. However, we could not find any sports-specific case definitions of NP in athletes. We recommend that in future studies researchers adopt acceptable case definitions based on available data.

Although validation of questionnaires in prevalence studies is important [19], only three studies [16,20,21] used a validated questionnaire (e.g., Questionnaire on Health and Working Conditions of High-Performance Marine Craft Populations and Teen Nordic Musculoskeletal Screening Questionnaire). Only Legault et al. [21] mentioned the reliability of their questionnaire. Considering the fact that validity (how well a questionnaire can 
Table 4. Neck pain prevalence in different reviewed studies with low to moderate risk of bias

\begin{tabular}{|c|c|c|c|c|c|}
\hline Study & Sport & $\begin{array}{c}\text { Point } \\
\text { prevalence }\end{array}$ & $\begin{array}{c}\text { One-year } \\
\text { prevalence }\end{array}$ & $\begin{array}{c}\text { Life-time } \\
\text { prevalence }\end{array}$ & Other prevalence (P) \\
\hline Villavicencio et al. [15] (2006) & Triathlon & NA & NA & $48.3 \%$ & Acute (66.7), subacute (11.9), chronic (21.4) \\
\hline Villavicencio et al. [13] (2007) & Triathlon & NA & NA & $47.6 \%$ & Acute (74.4), subacute (10.3), chronic (15.4) \\
\hline \multirow[t]{5}{*}{ Jonasson et al. [12] (2011) } & Weightlifting & NA & $52 \%$ & NA & One week P: weightlifting (41\%) \\
\hline & Wrestling & NA & $73 \%$ & NA & One week P: wrestling (45\%) \\
\hline & Orienteering & NA & $38 \%$ & NA & One week P: orienteering ( $8 \%)$ \\
\hline & Ice-hockey & NA & $65 \%$ & NA & One week P: ice-hockey (35\%) \\
\hline & Driving & NA & $47 \%$ & NA & One week P: driving (41\%) \\
\hline Nilsson et al. [16] (2013) & Skydiving & NA & $45 \%$ & NA & NA \\
\hline Bratland-Sanda et al. [20] (2015) & Fitness instructors & NA & NA & NA & Four week P: low IL $(38 \%)$, high IL $(43 \%)^{\text {b) }}$ \\
\hline Legault et al. [21] (2015) & NA & NA & NA & NA & Six month P: $26.3 \%$ \\
\hline
\end{tabular}

NA, not stated; IL, instruction loading.

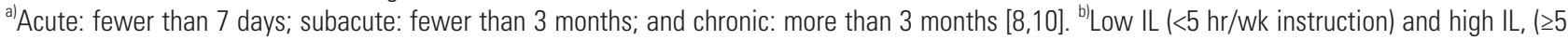
$\mathrm{hr} /$ wk instruction).

Table5. Neck Pain definition of different studies with low to moderate risk of bias

\begin{tabular}{ll}
$\begin{array}{l}\text { Study } \\
\text { Villavicencio et al. [15] (2006) }\end{array}$ & $\begin{array}{r}\text { The specificity or severity of the cervical pain was defined according to the duration of symptoms for the most } \\
\text { recent pain episode: fewer than } 7 \text { days (acute), fewer than } 3 \text { months (subacute), and more than } 3 \text { months } \\
\text { (chronic). }\end{array}$ \\
\begin{tabular}{ll} 
Villavicencio et al. [13] (2007) & The same as above \\
\hline Jonasson et al. [12] (2011) & NS \\
\hline $\begin{array}{l}\text { Nilsson et al. [16] (2013) } \\
\text { Bratland-Sanda et al. [20] (2015) }\end{array}$ & $\begin{array}{l}\text { Self-reported pain, ache, or discomfort in the last } 12 \text { month in a manikin with defined anatomical body areas (the } \\
\text { defined area for neck seemed like superior nuchal line to superior border of scapula) }\end{array}$ \\
\hline \begin{tabular}{l} 
Legault et al. [21] (2015) \\
\hline
\end{tabular} & Answer the following questions when considering the shaded area on the image: have you had neck symptoms \\
& (pain, ache, discomfort, throbbing) at any time during the last 6 months?
\end{tabular} \\
\hline
\end{tabular}

NS, not stated.

evaluate what it is intended to evaluate) and reliability (how consistent are responses to the questions) decrease the bias of prevalence studies, we encourage researchers to apply valid and reliable questionnaires in future studies.

Although a response rate higher than $75 \%$ is considered to indicate a low risk of bias, only one study [12] met this criterion. Some methods can increase the rate of response to a questionnaire, such as having clear questions and a simple layout, informing participants of the aim of the study and the benefits of the study results, and offering compensation for responding to the questionnaire [30]. If these methods are not applied, performing an analysis that shows no significant differences in demographic characteristics between responding and nonresponding athletes can decrease the risk of bias. Only one study, by
Nilsson et al. [16], performed such an analysis. Fortunately, in all studies $[12,13,15,16,20,21]$, the data were collected directly from the athletes, and this approach decreased the risk of bias.

To add to the existing body of knowledge, researchers need to be able to compare the prevalence of NP for each sport with data for other sports from other studies. The following recommendations may help decrease the risk of bias and increase the external and internal validity of such studies [19]: (1) The target population should be a close representative of national athletes in the country. (2) The sampling frame should select true samples from the population of athletes. (3) A random selection method should be applied. (4) The likelihood of nonresponse bias should be minimal. (5) The data should be collected directly from 
the athletes. (6) An acceptable case definition should be used. (7) A valid and reliable questionnaire should be used. (8) Data should be gathered by the same method for all athletes. (9) To decrease recall bias, the shortest prevalence period should be used, such as point prevalence, 1-week prevalence, or 1-year prevalence. (10) The reported prevalence should be based on appropriate numbers of athletes with NP and total numbers of athletes. (11) The levels of the athletes' expertise and experience should be evaluated.

\section{Limitations}

This systematic review investigated the prevalence of NP in athletes. We included studies that reported the prevalence of NP, excluding studies that only reported the prevalence of neck injury.

Due to the small number of studies that have investigated the prevalence of NP in athletes, in addition to differences between studies in the age, gender, and level of expertise of the athletes recruited, we could not pool the data and report a definite prevalence and time trend for NP over recent years. Most of the included athletes represented only a few sports, and thus we cannot generalize the results to other sports. Finally, due to lack of a professional translator, we excluded articles in languages other than English.

\section{Future research}

There is limited evidence to support a conclusion on the prevalence of NP in athletes. The lack of studies of the prevalence of NP in many popular sports, such as soccer, basketball, and tennis, is obvious. Therefore, it is recommended that in future studies researchers adopt a standard definition of NP and enroll a large sample of athletes selected randomly from the national sports population.

\section{Conclusions}

Although this review has limitations, it suggests that the prevalence of NP in athletes is relatively high. Some measures, such as specific exercises for neck muscles, protective devices, and rules for fair play, may help prevent NP in athletes. To evaluate the effects of various professional sports on the cervical spine, high-quality studies on different fields of sports are necessary. In addition, there is a lack of evidence about the relationship between physical activity and NP, a question that should be addressed in the future.

\section{Conflict of Interest}

No potential conflict of interest relevant to this article was reported.

\section{References}

1. Hoy DG, Protani M, De R, Buchbinder R. The epidemiology of neck pain. Best Pract Res Clin Rheumatol 2010;24:783-92.

2. Fejer R, Kyvik KO, Hartvigsen J. The prevalence of neck pain in the world population: a systematic critical review of the literature. Eur Spine J 2006;15:83448.

3. Vos T, Flaxman AD, Naghavi M, et al. Years lived with disability (YLDs) for 1160 sequelae of 289 diseases and injuries 1990-2010: a systematic analysis for the Global Burden of Disease Study 2010. Lancet 2012;380:2163-96.

4. Haldeman S, Carroll L, Cassidy JD, Schubert J, Nygren A; Bone and Joint Decade 2000-2010 Task Force on Neck Pain and Its Associated Disorders. The Bone and Joint Decade 2000-2010 Task Force on Neck Pain and Its Associated Disorders: executive summary. Spine (Phila Pa 1976) 2008;33(4 Suppl):S5-7.

5. Hogg-Johnson S, van der Velde G, Carroll LJ, et al. The burden and determinants of neck pain in the general population: results of the Bone and Joint Decade 2000-2010 Task Force on Neck Pain and Its Associated Disorders. Spine (Phila Pa 1976) 2008;33(4 Suppl):S39-51.

6. Shariat A, Tamrin SB, Arumugam M, Danaee M, Ramasamy R. Prevalence rate of musculoskeletal discomforts based on severity level among office workers. Acta Medica Bulgarica 2016;43:54-63.

7. Yang H, Haldeman S, Nakata A, Choi B, Delp L, Baker D. Work-related risk factors for neck pain in the US working population. Spine (Phila Pa 1976) 2015;40:184-92.

8. Heneweer H, Vanhees L, Picavet HS. Physical activity and low back pain: a U-shaped relation? Pain 2009;143:21-5. 
9. Trompeter K, Fett D, Platen P. Prevalence of back pain in sports: a systematic review of the literature. Sports Med 2017;47:1183-207.

10. Noormohammadpour P, Rostami M, Mansournia MA, Farahbakhsh F, Pourgharib Shahi MH, Kordi R. Low back pain status of female university students in relation to different sport activities. Eur Spine J 2016;25:1196-203.

11. Schmidt CP, Zwingenberger S, Walther A, et al. Prevalence of low back pain in adolescent athletes: an epidemiological investigation. Int J Sports Med 2014;35:684-9.

12. Jonasson P, Halldin K, Karlsson J, et al. Prevalence of joint-related pain in the extremities and spine in five groups of top athletes. Knee Surg Sports Traumatol Arthrosc 2011;19:1540-6.

13. Villavicencio AT, Hernandez TD, Burneikiene S, Thramann J. Neck pain in multisport athletes. J Neurosurg Spine 2007;7:408-13.

14. Weiss BD. Nontraumatic injuries in amateur long distance bicyclists. Am J Sports Med 1985;13:187-92.

15. Villavicencio AT, Burneikiene S, Hernandez TD, Thramann J. Back and neck pain in triathletes. Neurosurg Focus 2006;21:E7.

16. Nilsson J, Friden C, Buren V, Westman A, Lindholm P, Ang BO. Musculoskeletal pain and related risks in skydivers: a population-based survey. Aviat Space Environ Med 2013;84:1034-40.

17. Moher D, Liberati A, Tetzlaff J, Altman DG; PRISMA Group. Preferred reporting items for systematic reviews and meta-analyses: the PRISMA statement. Ann Intern Med 2009;151:264-9.

18. Stroup DF, Berlin JA, Morton SC, et al. Meta-analysis of observational studies in epidemiology: a proposal for reporting. Meta-analysis Of Observational Studies in Epidemiology (MOOSE) group. JAMA 2000;283:2008-12.

19. Hoy D, Brooks P, Woolf A, et al. Assessing risk of bias in prevalence studies: modification of an existing tool and evidence of interrater agreement. J Clin Epidemiol 2012;65:934-9.

20. Bratland-Sanda S, Sundgot-Borgen J, Myklebust G.
Injuries and musculoskeletal pain among Norwegian group fitness instructors. Eur J Sport Sci 2015;15:78492.

21. Legault EP, Descarreaux M, Cantin V. Musculoskeletal symptoms in an adolescent athlete population: a comparative study. BMC Musculoskelet Disord 2015;16:210.

22. Wojcik M, Siatkowski I. Assessment of spine pain presence in children and young persons studying in ballet schools. J Phys Ther Sci 2015;27:1103-6.

23. Guzman J, Hurwitz EL, Carroll LJ, et al. A new conceptual model of neck pain: linking onset, course, and care: the Bone and Joint Decade 2000-2010 Task Force on Neck Pain and Its Associated Disorders. Spine (Phila Pa 1976) 2008;33(4 Suppl):S14-23.

24. Huffman EA, Yard EE, Fields SK, Collins CL, Comstock RD. Epidemiology of rare injuries and conditions among United States high school athletes during the 2005-2006 and 2006-2007 school years. J Athl Train 2008;43:624-30.

25. Biasca N, Wirth S, Tegner Y. The avoidability of head and neck injuries in ice hockey: an historical review. Br J Sports Med 2002;36:410-27.

26. Roos L, Taube W, Zuest P, Clenin G, Wyss T. musculoskeletal injuries and training patterns in junior elite orienteering athletes. Biomed Res Int 2015;2015:259531.

27. Deakon RT. Chronic musculoskeletal conditions associated with the cycling segment of the triathlon; prevention and treatment with an emphasis on proper bicycle fitting. Sports Med Arthrosc Rev 2012;20:200-5.

28. Deyo RA, Dworkin SF, Amtmann D, et al. Report of the NIH task force on research standards for chronic low back pain. Spine (Phila Pa 1976) 2014;39:112843.

29. Dionne CE, Dunn KM, Croft PR, et al. A consensus approach toward the standardization of back pain definitions for use in prevalence studies. Spine (Phila Pa 1976) 2008;33:95-103.

30. Jaykaran. How to increase response rate to a questionnaire study? Indian J Pharmacol 2011;43:93-4. 